\title{
Human papillomavirus vaccine coverage among female Australian adolescents: success of the school-based approach
}

\section{Julia M L Brotherton BMed(Hons) MPH(Hons), FAFPHM Medical Director, and PhD Candidate \\ Sharron L Murray RN, RM GradDipChildHealth, Public Health Nurse (Immunisation) \\ Madeline A Hal \\ Public Health Nurse \\ Lynne K Andrewartha BHSC(Nur), Former Public Health Nurs (Immunisation) \\ Carolyn A Banks Manager $^{6}$ \\ Dennis Meijer BA, MHL \\ Senior Policy Analyst \\ Helen C Pitche Immunisation Nurse \\ Megan M Scully BSc(Nsg), DPH, MHA Nursing Coordinator ${ }^{9}$ \\ Luda Molchanoff \\ Advanced Nurs} Management Facilitator ${ }^{10}$

1National HPV Vaccination Program Registe Victorian Cytology Service Melbourne, VIC

2 Discipline of Paediatrics and Child Health,

University of Sydney,

Sydney, NSW.

3 Centre for Disease Control, Darwin, NT.

4 Queensland Health. Brisbane, QLD.

5 Communicable Diseases Control Unit,

Department of Health

and Human Services, Hobart, TAS

6 Communicable Diseases

Control, ACT Health, Canberra, ACT.

7 Communicable Diseases Branch, Health Protection NSW, NSW Health Sydney, NSW.

8Department of Health Melbourne, VIC

9 Communicable Diseas Control Directorate WA Health, Perth, WA.

10Department of Health and Ageing, Adelaide, SA.

jbrother@vcs.org.au

MJA 2013; 199: 614-617 doi: 10.5694/mjal3.10272 n November 2006, a governmentfunded vaccination program using quadrivalent prophylactic human papillomavirus (HPV) vaccine (Gardasil; Merck Sharp and Dohme) was announced for Australian females. The program included routine schoolbased vaccination of 12-13-year-olds and a time-limited "catch-up program" for females aged up to 17 years at school and for those aged up to 26 years (as at 2007) through general practitioners and community providers. From 2013, HPV vaccination was extended to boys (aged 12-13 years, and two catch-up cohorts aged 14-15 years). The four HPV types against which the vaccine provides protection (when administered before infection) cause almost $80 \%$ of cervical cancers in Australia (types 16 and 18) ${ }^{1}$ and nearly all genital warts (types 6 and 11). ${ }^{2}$ The vaccine is a three-dose course given over 6 months, delivered to girls at school (aged 12-17 years) between April 2007 and December 2008, with courses to be completed by end December 2009.

Program promotion was coordinated nationally. States and territories delivered the program in their schools using methods already in use for other adolescent vaccines, except for Queensland, which commenced school-based vaccination programs in 2007. In each jurisdiction, the state health department was responsible for vaccine purchasing and distribution, developing consent forms and information, vaccination protocols and central coordination of the school-based program. It should be noted that education and health departments have distinct and separate functions, and that immunisation is permitted in schools on a goodwill basis rather than through specific legislative arrangements or mandated shared responsibility for student health. Thus the administration of the program within individual schools was negotiated at the school level.

All jurisdictions used qualified school-based immunisation teams, usually including nurses. In rural and

Objective: To describe quadrivalent human papillomavirus (HPV) vaccination coverage achieved in the HPV vaccination catch-up program for girls aged 12-17 years.

Design: Analysis of data from the Australian National HPV Vaccination Program Register.

Participants: Girls aged 12-17 years as at 30 June 2007.

Main outcome measures: HPV vaccine coverage by dose (1,2 and 3), age and state of residence, using Australian Bureau of Statistics estimates of resident populations as the denominator.

Results: Notified vaccination coverage for girls aged 12-17 years nationally was $83 \%$ for dose $1,78 \%$ for dose 2 and $70 \%$ for dose 3 . The Australian Capital Territory and Victoria recorded the highest three-dose coverage for the 12-17year-old cohort overall at $75 \%$. The highest national three-dose coverage rate by age was achieved in 12-year-olds (74\%). In Queensland, coverage among Indigenous girls compared with non-Indigenous girls was lower with each dose (lower by $4 \%$ for dose 1, 10\% for dose 2 and 15\% for dose 3 ). This pattern was not seen in the NT, where initial coverage was 17\% lower among Indigenous girls, but the course completion rate among those who started vaccination was identical (84\%).

Conclusions: The catch-up HPV vaccination program delivered over 1.9 million doses of HPV vaccine to girls aged 12-17 years, resulting in 70\% of girls in this age group being fully vaccinated. The range in coverage achieved and the lower uptake documented among Indigenous girls suggest that HPV vaccination programs can be further improved.

remote areas, some used contracted GPs or community health providers and, in the Northern Territory, program nurses supported delivery by remote area staff. Responsibility for the local coordination of the school teams differs by jurisdiction, with Victoria, Tasmania, South Australia and Qld predominantly using councils, Western Australia using councils and the Child and Adolescent Health Service in Perth, and an area health service model in the seven regional areas. New South Wales and the Australian Capital Territory use an area health service model.

School attendance among adolescent girls in Australia is high, with 98.5\% of those aged 14 years enrolled in school, and $83 \%$ of those enrolled completing the final year of high school (range 56\% in the NT to $93 \%$ in the ACT). ${ }^{3}$ School-based HPV vaccinations were delivered in high school with two exceptions: in WA, and in some local government areas of Tas, girls were vaccinated in the final year of primary school at age 11-12 years. In Tas parents were given the option of obtaining vaccination from their GP.
This article documents the coverage achieved in girls aged 12-17 years during the catch-up program, including the first estimates of Indigenous coverage, as estimated by the National HPV Vaccination Program Register (NHVPR). The NHVPR was established under Commonwealth legislation, which mandates what information can be collected (with consent), and commenced in mid 2008. Its main functions are to support the program through monitoring of coverage and to provide information to vaccine providers and those receiving the vaccine. ${ }^{4}$

\section{Methods}

The NHVPR systematically collects school program HPV vaccination data from every state and territory. Two jurisdictions (Qld and the NT) have state-based immunisation registers, which provide regular electronic data uploads. Initially, both Tas and SA collected data centrally and provided it to the NHVPR when it became operational. Thereafter, as was the case in Vic throughout, each council 
Australian HPV vaccination coverage on the National HPV Vaccination Program Register as at 30 June 2011

\begin{tabular}{|c|c|c|c|c|c|c|c|c|c|}
\hline \multirow[b]{2}{*}{ State } & \multirow[b]{2}{*}{ Total doses } & \multirow[b]{2}{*}{ Dose } & \multicolumn{7}{|c|}{ Age in years (as at 30 June 2007) } \\
\hline & & & 12 & 13 & 14 & 15 & 16 & 17 & $12-17$ \\
\hline \multirow{3}{*}{$\begin{array}{l}\text { Australian } \\
\text { Capital } \\
\text { Territory }\end{array}$} & 32319 & 1 & $89 \%$ & $91 \%$ & $89 \%$ & $88 \%$ & $87 \%$ & $85 \%$ & $88 \%$ \\
\hline & & 2 & $87 \%$ & $87 \%$ & $85 \%$ & $83 \%$ & $81 \%$ & $79 \%$ & $84 \%$ \\
\hline & & 3 & $79 \%$ & $80 \%$ & $77 \%$ & $76 \%$ & $72 \%$ & $68 \%$ & $75 \%$ \\
\hline \multirow{3}{*}{$\begin{array}{l}\text { New South } \\
\text { Wales }\end{array}$} & 628101 & 1 & $82 \%$ & $83 \%$ & $83 \%$ & $85 \%$ & $82 \%$ & $80 \%$ & $82 \%$ \\
\hline & & 2 & $79 \%$ & $79 \%$ & $79 \%$ & $81 \%$ & $77 \%$ & $74 \%$ & $78 \%$ \\
\hline & & 3 & $73 \%$ & $73 \%$ & $72 \%$ & $75 \%$ & $70 \%$ & $65 \%$ & $71 \%$ \\
\hline \multirow{3}{*}{$\begin{array}{l}\text { Northern } \\
\text { Territory }\end{array}$} & 23036 & 1 & $92 \%$ & $88 \%$ & $82 \%$ & $86 \%$ & $87 \%$ & $81 \%$ & $86 \%$ \\
\hline & & 2 & $87 \%$ & $83 \%$ & $77 \%$ & $81 \%$ & $80 \%$ & $73 \%$ & $80 \%$ \\
\hline & & 3 & $81 \%$ & $76 \%$ & $70 \%$ & $74 \%$ & $72 \%$ & $63 \%$ & $73 \%$ \\
\hline \multirow[t]{3}{*}{ Queensland } & 402516 & 1 & $84 \%$ & $84 \%$ & $85 \%$ & $86 \%$ & $85 \%$ & $80 \%$ & $84 \%$ \\
\hline & & 2 & $80 \%$ & $79 \%$ & $81 \%$ & $81 \%$ & $79 \%$ & $71 \%$ & $79 \%$ \\
\hline & & 3 & $73 \%$ & $72 \%$ & $72 \%$ & $73 \%$ & $71 \%$ & $58 \%$ & $70 \%$ \\
\hline \multirow{3}{*}{$\begin{array}{l}\text { South } \\
\text { Australia }\end{array}$} & 137085 & 1 & $82 \%$ & $84 \%$ & $83 \%$ & $82 \%$ & $81 \%$ & $78 \%$ & $82 \%$ \\
\hline & & 2 & $79 \%$ & $80 \%$ & $79 \%$ & $77 \%$ & $75 \%$ & $70 \%$ & $77 \%$ \\
\hline & & 3 & $70 \%$ & $73 \%$ & $70 \%$ & $67 \%$ & $65 \%$ & $59 \%$ & $67 \%$ \\
\hline \multirow[t]{3}{*}{ Tasmania } & 42084 & 1 & $79 \%$ & $77 \%$ & $79 \%$ & $81 \%$ & $74 \%$ & $72 \%$ & $77 \%$ \\
\hline & & 2 & $75 \%$ & $71 \%$ & $72 \%$ & $74 \%$ & $66 \%$ & $62 \%$ & $70 \%$ \\
\hline & & 3 & $68 \%$ & $64 \%$ & $63 \%$ & $65 \%$ & $57 \%$ & $52 \%$ & $62 \%$ \\
\hline \multirow[t]{3}{*}{ Victoria } & 490586 & 1 & $87 \%$ & $86 \%$ & $86 \%$ & $87 \%$ & $87 \%$ & $84 \%$ & $86 \%$ \\
\hline & & 2 & $84 \%$ & $83 \%$ & $82 \%$ & $83 \%$ & $82 \%$ & $79 \%$ & $82 \%$ \\
\hline & & 3 & $79 \%$ & $76 \%$ & $74 \%$ & $75 \%$ & $75 \%$ & $71 \%$ & $75 \%$ \\
\hline \multirow{3}{*}{$\begin{array}{l}\text { Western } \\
\text { Australia }\end{array}$} & 173206 & 1 & $77 \%$ & $78 \%$ & $78 \%$ & $75 \%$ & $72 \%$ & $64 \%$ & $74 \%$ \\
\hline & & 2 & $73 \%$ & $74 \%$ & $73 \%$ & $69 \%$ & $66 \%$ & $56 \%$ & $68 \%$ \\
\hline & & 3 & $66 \%$ & $65 \%$ & $64 \%$ & $61 \%$ & $56 \%$ & $46 \%$ & $60 \%$ \\
\hline \multirow[t]{3}{*}{ All Australia } & 1928933 & 1 & $83 \%$ & $83 \%$ & $84 \%$ & $84 \%$ & $83 \%$ & $79 \%$ & $83 \%$ \\
\hline & & 2 & $80 \%$ & $80 \%$ & $79 \%$ & $80 \%$ & $77 \%$ & $72 \%$ & $78 \%$ \\
\hline & & 3 & $74 \%$ & $73 \%$ & $71 \%$ & $72 \%$ & $69 \%$ & $62 \%$ & $70 \%$ \\
\hline
\end{tabular}

reported data to the NHVPR directly. Most councils use electronic immunisation databases from which they extract HPV vaccination data. In NSW, centralised annual data were uploaded to the NHVPR after batched scanning of consent forms. In WA, electronic data were uploaded annually from centrally collated data. In the $\mathrm{ACT}$, a temporary database was used until the NHPVR was established thereafter data were entered directly through the web portal.

Throughout the catch-up program, females could receive doses missed at school, or the complete course if they were not in school, from their GP or community health provider. GPs were paid $\$ 6$ per dose notified, but notifications were not compulsory. Doses could be notified by posting hard copy records or printouts from practice management software, or electronically through the web portal. ${ }^{4}$

Coverage was calculated by dose for Australian girls aged $12-17$ years as at 2007. Only valid doses were included (ie, doses meeting recommended mini- mum intervals or forming part of a clinically complete course as per the Australian Government's Chief Medical Officer's guidelines). ${ }^{5}$ Doses notified from all provider types were included (school immunisation program providers and other providers such as GPs). Data were extracted from the NHVPR as at 30 June 2011. The denominator population used was the Australian Bureau of Statistics (ABS) estimate of resident population for girls aged 12-17 years as at 30 June 2007. Although the NHVPR collects Indigenous status, this is not a mandatory field, as per the underlying legislation, and not all jurisdictions included this field on their consent forms. Only in Qld and the NT was Indigenous status reported with sufficient completeness to use NHVPR data to assess coverage. In Qld, 5.8\% identified as Indigenous and $14 \%$ had unknown or unreported status; and in the NT, 38.8\% identified as Indigenous and 3.7\% had unknown or unreported status. The denominator was estimated for Indigenous girls in Qld and the NT using experimental
ABS estimates based on 2006 census data. From these data, $6 \%$ of girls aged $12-17$ years in Qld and $43.5 \%$ in the NT identified as Indigenous.

NHVPR data were approved for release by the data custodian, the Commonwealth Department of Health and Ageing. No ethics approval was required for this study: data are collected by the NHVPR under legislation that allows for their use in monitoring and evaluation.

\section{Results}

\section{Coverage}

Of doses notified in girls aged 12-17 years, GPs delivered $14 \%$ of doses, ranging by age from $8 \%$ in 12 -yearolds to $28 \%$ in 17 -years-olds, and by state from $5 \%$ in the NT to $24 \%$ in Tas. National and jurisdictional coverage estimates by age are presented in the Box and show high coverage in the overall cohort of dose $1(83 \%)$, dose 2 $(78 \%)$ and dose $3(70 \%)$. The highest 1-dose coverage achieved, by state, was in 13-year-olds in the ACT (91\%) and in 12-year-olds in the NT (92\%). The highest three-dose coverage by age group nationally was in 12-yearolds (74\%). The ACT and Vic recorded the highest three-dose coverage for the 12-17-year-old cohort at $75 \%$.

\section{Estimates of Indigenous coverage}

In Qld, coverage by dose among girls aged 12-17 years who identified as being of Aboriginal or Torres Strait Islander background was $80 \%$ for dose $1,69 \%$ for dose 2 and $54 \%$ for dose 3, while in the NT it was and $76 \%$ for dose $1,71 \%$ for dose 2 and $64 \%$ for dose 3. Although in Qld dose 1 coverage was only slightly lower than that notified for Qld girls overall, with each dose a larger disparity in coverage was evident $(4 \%, 10 \%$ and $15 \%$ gap). In the NT there was a larger discrepancy in the number of Indigenous girls starting the course compared with non-Indigenous girls (17\%). However, the completion rate once started was the same for both groups (84\%). Local-level data and experience in the NT showed that vaccine uptake in schools with a high proportion of Indigenous boarding students was significantly lower because of difficulties returning consent forms. 
Discussion

While the requirement to rapidly implement the program was challenging, ${ }^{6}$ the coverage achieved in adolescents through the predominantly school-based HPV vaccination catch-up program represents a remarkable achievement with $70 \%$ of 12-17-year-old girls Australia-wide completely vaccinated. Combined with the coverage achieved in the 1826-year-old catch-up cohort, ${ }^{7}$ at least half of Australia's females who were aged 12-26 years on 30 June 2007 are fully vaccinated. This significant and rapidly achieved coverage has been correlated with a marked decline in genital warts, ${ }^{8}$ vaccine-type HPV prevalence 9 and high-grade cervical disease in young women. ${ }^{10}$

Doses delivered in school programs should be completely recorded, except where an individual did not consent for data to be provided to the NHVPR. The number of individuals opting off the Register in this way is unknown but thought to be very low (NHVPR received 27 requests to opt off the Register from females aged 12-18 years between 2007 and 2011). Data completeness for non-school-delivered doses may vary across the country. In Tas, which had the highest percentage of the cohort with GP notifications, under-notification from general practice may be contributing to the apparently lower-than-average coverage. Some states, such as NSW, did not use the NHVPR's history statements, but sent a letter to girls with incomplete courses, or released overdue-dose reports to general practices. Where these functions were used, in some states they resulted in large numbers of additional notifications.

Our data suggest that coverage achieved among Indigenous girls is substantial but probably lower than in non-Indigenous girls. School retention and attendance rates are lower for Indigenous students in Qld compared with non-Indigenous students. For example, in 2008, $47.5 \%$ of Indigenous students attended 90\%-100\% of the school year compared with $71.2 \%$ of non-Indigenous students. ${ }^{11}$ Poorer attendance makes delivering a three-dose vaccine schedule substantially more challenging. It is important therefore that culturally appropriate information (developed before such a campaign and developed with communities), and a vaccine supply, are available in community health services that are attended by adolescent Indigenous girls, and that flexibility of age at administration allows vaccination either in later primary school or potentially in the future by allowing funded catch-up to older ages in areas where age incidence rates for HPVrelated disease are above national rates, eg, East Arnhem Land, NT. In the NT, the program used a combination of school and community clinics in order to reach Indigenous girls, allocated additional resources for remote areas and developed appropriate communication resources supported by local language community radio announcements. Particular challenges in ensuring equity of coverage, especially for remote-dwelling girls, included busy school and community schedules, competing priorities such as the federal government NT National Emergency Response affecting the timeliness of vaccination, unforeseen events such as funerals and failure of vaccine delivery, a lack of accommodation and limited community resources in some remote communities. However, women in many communities embraced the program and developed their own initiatives to encourage girls to complete the course. HPV program nurses assisted schools by raising awareness and actively seeking consent from parents of boarding students when visiting remote communities. ${ }^{12}$

While it is likely that the program is cost-effective at $70 \%$ coverage, the model that informed the Pharmaceutical Benefits Advisory Committee decision used a base coverage of $80 \%$ in 12-year-olds. ${ }^{13}$ While Australian coverage is high compared with countries using non-school-based approaches, ${ }^{14,15}$ some countries with established school-based programs have achieved even higher coverage. Coverage in the target cohort in Scotland has exceeded $90 \%$ for three doses for over 4 years running. ${ }^{16}$ The Scottish program was highly organised, taking a project management approach to program implementation, and using existing comprehensive community health data systems and registers, which are supported by a unique identification number for each person. ${ }^{17}$ For Australia to achieve higher coverage, a systemsbased approach to identifying and minimising barriers may be required. Despite the program being national, implementation occurs at a state, and within-state level, with differing systems in place. For example, a Victorian survey of councils documented a wide variation in the number of schools per council, access to class lists, use of translated resources, follow-up of consent forms and preimmunisation education. ${ }^{18}$

The high uptake of dose 1 suggests that the vaccine is widely acceptable to parents and adolescents. An evaluation in British Columbia of reasons for non-consent found that concern about the safety and newness of the vaccine and lack of information were important barriers in its school-based program. ${ }^{19}$ Similar concerns about the vaccine being too new were reported during commissioned market research by parents whose children did not receive the vaccine at school in Qld (personal communication, Karen Peterson, Director, Qld Health Immunisation Program, 2011). Parents and girls in a qualitative NSW study also desired more information. ${ }^{20}$

It is unclear how many parents are not consenting to vaccination due to non-receipt of the consent form, which is usually given to the schoolgirl to take home. Not all states currently monitor consent form return rates, due to restrictions in the provision of student lists by schools. Research in Vic found that having a process to follow-up non-returned consent forms was a characteristic of councils with higher HPV vaccination coverage. ${ }^{18}$ Qld market research showed that for $18 \%$ of missed vaccinations (all vaccines), parents reported never receiving the consent form. All these parents said they were not advised that the consent form was not returned (personal communication, Karen Peterson, Director, Qld Health Immunisation Program, 2011). In WA, research showed that sending a second consent form was more effective than a letter, phone call or school incentives for improving return rates. ${ }^{21}$ Significant efforts to streamline such processes in WA have led to rising coverage: in 2010, coverage in 12 -year-olds was $84 \%$ for dose $1,82 \%$ for dose 2 and $75 \%$ for dose 3 . In SA, increasing numbers of consent forms 
have been returned since the catchup, with $81 \%$ returned in 2010 and $89.6 \%$ in 2011.

Identifying the barriers to completing the three-dose series is important to allow the programs to overcome them. Research is ongoing, but some states have already identified key barriers. The main reasons for non-completion given by parents of Qld schoolgirls were school absence and receipt of vaccination elsewhere (personal communication, Karen Peterson, Director, Qld Health Immunisation Program, 2011). Similarly, an SA study, which contacted parents of under-immunised girls, found strong support for schedule completion but that absence from school, lack of awareness of vaccination status and difficulties in attending follow-up clinics impeded compliance. ${ }^{22}$ International data and a study of Victorian women aged 18-26 years have also found that issues relating to lack of time and inconvenience or logistical barriers, rather than side effects or negative vaccination experiences, are major drivers of failure to complete the course. ${ }^{23,24}$ Ideally, throughout the country, parents should be made aware when a dose is missed and provided with a specific, accessible way to ensure the dose is received.

In summary, the catch-up schoolbased HPV vaccination program delivered over 1.9 million doses of vaccine to girls aged 12-17 years, resulting in $70 \%$ being fully vaccinated. Given the rapid timelines for implementation of the program, this is a particularly remarkable achievement. Ongoing review and evaluation of school-based programs is occurring across Australia ${ }^{18,25,26}$ and promises to further improve HPV vaccination coverage. The current campaign supporting the expansion of the program to boys incorporates some of the lessons learned to date and includes strong messages about the need to return the consent form and the importance of completing all three doses. The under-reporting of Indigenous status to the NHVPR requires engagement and analysis from all stakeholders and the development of a targeted strategy for improvement, acknowledging that some improvements have already occurred since the catch-up program.
Any strategy should be underpinned by best-practice guidelines, which strongly support the need to change the legislation to make reporting mandatory. ${ }^{27}$ Hopefully the expansion of the program to include males will normalise receipt of HPV vaccination as just a routine part of the vaccination schedule.

Acknowledgements: The NHVPR is owned by the Department of Health and Ageing and managed by the Victorian Cytology Service. We wish to thank all the immunisation program managers and the immunisation teams who delivered the program across Australia, and to specifically acknowledge Vicki Bryant, Kerry Nettle, Genevieve Chappell, Lesley Rowlands, Karen Winch, Christine Selvey and Karen Peterson for assistance with the preparation of this pape.

Competing interests: Julia Brotherton was a partner investigator on an Australian Research Council linkage grant on which bioCSL was a partner investigator.

Received 5 Mar 2013, accepted 8 Aug 2013.

1 Brotherton JM. How much cervical cancer in Australia is vaccine preventable? A metaanalysis. Vaccine 2008; 26: 250-256.

2 Ball SL, Winder DM, Vaughan K, et al. Analyses of human papillomavirus genotypes and viral loads in anogenital warts. J Med Virol 2011; 83: 1345-1350.

3 Australian Bureau of Statistics. Schools, Australia, 2010. Canberra: ABS. (ABS Cat. No. 4221.0.) http://www.abs.gov.au/AUSSTATS/ abs@.nsf/Lookup/4221.0Main+Features12010? OpenDocument (accessed Jan 2013).

4 Gertig DM, Brotherton JML, Saville M. Measuring human papillomavirus (HPV) vaccination coverage and the role of the National HPV Vaccination Program Register, Australia. Sex Health 2011; 8: 171-178.

5 Chief Medical Officer. Guidance on revaccination where HPV vaccine doses have been given at less than recommended minimum intervals: January 2009. Canberra: Department of Health and Ageing, 2009. http://www.health.gov.au/ internet/immunise/publishing.nsf/Content/ cmo-full-advice-hpv-cnt/\$File/CMO-full-advicehpv.pdf (accessed Oct 2013).

6 Leask J, Jackson C, Trevena L, et al. Implementation of the Australian HPV vaccination program for adult women: qualitative key informant interviews. Vaccine 2009; 27: 5505-5512.

7 Brotherton J, Gertig D, Chappell G, et al. Catching up with the catch-up: HPV vaccination coverage data for Australian women aged 18-26 years from the National HPV Vaccination Program Register. Commun Dis Intell Q Rep 2011; 35: 197-201.

8 Ali H, Donovan B, Wand $\mathrm{H}$, et al. Genital warts in young Australians five years into national human papillomavirus vaccination programme: national surveillance data. BMJ 2013; 346: f2032.

9 Tabrizi SN, Brotherton JM, Kaldor JM, et al. Fall in human papillomavirus prevalence following a national vaccination program. J Infect Dis 2012; 206: 1645-1651.

10 Brotherton JM, Fridman M, May CL, et al. Early effect of the HPV vaccination programme on cervical abnormalities in Victoria, Australia: an ecological study. Lancet 2011; 377: 2085-2092.

11 Queensland Department of Education and Training. Closing the Gap: education strategy. Brisbane: Queensland Government. http:// deta.qld.gov.au/indigenous/pdfs/closing-gap13072011.pdf (accessed Jan 2013).

12 Northern Territory Department of Health. NT HPV Vaccination Program Remote Project Report
June 2009. Dr Rosalind Webby, Head of Immunisation, NT Department of Health

13 Kulasingam S, Connelly L, Conway E, et al. A cost-effectiveness analysis of adding a human papillomavirus vaccine to the Australian National Cervical Cancer Screening Program. Sex Health 2007; 4: 165-175.

14 Centers for Disease Control and Prevention. National and state vaccination coverage among adolescents aged 13-17 years - United States, 2011. MMWR Morb Mortal Wkly Rep 2012; 61: 671-677.

15 Fagot JP, Boutrelle A, Ricordeau P, et al. HPV vaccination in France: uptake, costs and issues fo the National Health Insurance. Vaccine 2011; 29: 3610-3616.

16 Information Services Division Scotland. HPV immunisation uptake statistics. HPV Immunisation Programme - School Year 2011/12 Publication date - 25 September 2012. http:// www.isdscotland.org/Health-Topics/ChildHealth/Publications/2012-09-25/2012-09-25HPV-Uptake-Report.pdf?49483889342 (accessed Jan 2013)

17 Potts A, Sinka K, Love J, et al. High uptake of HPV immunisation in Scotland - perspectives on maximising uptake. Euro Surveill 2013; 18 : pii=20593.

18 O'Donnell H, Broun K, Mullins R. A new partnership approach to school-based HPV immunisation in Victoria. Presented at the 13th National Immunisation Conference; 2012 Jun 19-21; Darwin, NT, Australia.

19 Ogilvie G, Anderson M, Marra F, et al. A population-based evaluation of a publicly funded, school-based HPV vaccine program in British Columbia, Canada: parental factors associated with HPV vaccine receipt. PLOS Med 2010; 7: el000270.

20 Cooper Robbins SC, Bernard D, McCaffery K, et al. "Is cancer contagious?": Australian adolescent girls and their parents: making the most of limited information about HPV and HPV vaccination. Vaccine 2010; 28: 3398-3408.

21 Mak DB, Bulsara M, Goggin LS, Effler PV. Resending a consent form and information package to non-responders increases schoolbased consent return rate. Aust N Z J Public Health 2011; 35: 89-90.

22 Watson M, D'Onise K, Lynch J, Brotherton JML. What are the barriers to better three-dose coverage with HPV vaccination in school based programs? Aust N Z J Public Health 2013. In press.

23 Brotherton JML, Mullins RM. Will vaccinated women attend cervical screening? A population based survey of human papillomavirus vaccination and cervical screening among young women in Victoria, Australia. Cancer Epidemiol 2012; 36: 298-302.

24 Kouyoumdjian FG, Bailowitz A. Completion of the human papillomavirus vaccine series in females attending an urban immunization clinic. Pediatr Infect Dis J 2011; 30: 718-719.

25 Watson M, Shaw D, Molchanoff L, McInnes C. Challenges, lessons learned and results following the implementation of a human papilloma virus school vaccination program in South Australia. Aust N Z J Public Health 2009; 33: 365-370.

26 Queensland Health Immunisation Program. Evaluation of the School Based Vaccination Program (2007-2009) Stakeholders' report. Brisbane: Queensland Government. http://www.health.qld.gov.au/immunisation/ documents/sbvpevaluation.pdf (accessed Jan 2013).

27 Australian Institute of Health and Welfare. National best practice guidelines for collecting Indigenous status in health data sets. Canberra: AlHW, 2010. (AlHW Cat. No. IHW 29.) http://www.aihw. gov.au/publication-detail/ ? 